\title{
Health-Promoting Behaviours of University Nursing Students in Jordan
}

\author{
Omayyah S. Nassar*, Abeer M. Shaheen \\ Maternal and Child Health Nursing Department, Faculty of Nursing, The University of Jordan, Amman, Jordan \\ Email: ${ }^{*}$ omayah64@live.com, ${ }^{*}$ o.Nassar@ju.edu.jo, abeer shahen@yahoo.com, abeer.Shaheen@ju.edu.jo
}

Received 19 September 2014; revised 5 November 2014; accepted 20 November 2014

Copyright (C) 2014 by authors and Scientific Research Publishing Inc.

This work is licensed under the Creative Commons Attribution International License (CC BY). http://creativecommons.org/licenses/by/4.0/

c) (i) Open Access

\begin{abstract}
The purpose of this study was to determine health-promoting behaviours of university nursing students in Jordan. This descriptive cross-sectional study used convenient sampling technique to recruit 167 undergraduate nursing students in Jordan. Data were collected by using an Arabic version of Health-Promoting Lifestyle Profile II. The study results revealed that the mean item score for total Health-Promoting Lifestyle Profile II was $(127.24 \pm 21.03)$. The students obtained highest scores in spiritual growth $(25.04 \pm 4.70)$ and lowest in physical activity subscales $(16.27 \pm$ 5.21). Significant difference was found between Health-Promoting Lifestyle Profile II subscales (stress management, health responsibility, and interpersonal relations) and students' age and gender.
\end{abstract}

\section{Keywords}

Jordan, Nursing Students, Health-Promoting Behaviours

\section{Introduction}

It is reported that morbidity and mortality attributed to non-communicable diseases account for nearly half of the global burden of disease and about $60 \%$ of global deaths [1]. In particular, approximately $80 \%$ of deaths attributed to non-communicable diseases occur in developing countries [2]. Jordan is one of the developing countries, with a current population of 6,581,368 [3]. Young people (18 - 34 years old) account for 36\% of the Kingdom's population. Unfortunately, there is a tremendous increase in the prevalence of lifestyles related illness such as diabetes, hypertension, and cardiovascular diseases among youth population. Furthermore, risk factors associated with these diseases, for example, obesity, smoking, and sedentary lifestyle are becoming common in Jordan and might witness a frightening increase by the year 2050 [4]. On the other side, the causal

${ }^{*}$ Corresponding author. 
relationships between nutrition, food and physical activity and non-communicable diseases are well recognized [5]. Health-promoting behaviours comprise six components including health responsibility, physical activity, nutrition, interpersonal relations, spiritual growth, and stress management. These behaviours are part of daily activities of life that impact individual happiness, values, and well-being [6].

Moreover, exhibiting healthy lifestyle behaviours is an important component in maintaining health [5], and entails a positive approach to living and a mean of increasing well-being and self-actualization [7].

There is evidence that unhealthy lifestyles among youths are strongly linked to disabilities and health problems in adulthood [8] [9]. Therefore, if these behaviours are detected and changed at an early stage, many effects of health-risk factors among adults are avoidable [10]. University students constitute a large part of the young population [8]. Previous studies on health-promoting behaviours of university students from different specialities [11]-[14] and students of nursing and health sciences [6] [15]-[26] indicated a high level of risky health behaviours among students. Therefore, it is essential for the promotion of their healthy growth to investigate their healthy lifestyle behaviours and influential factors [8].

University health faculties give great attention to health promotion in their curriculum. Students in these faculties are in close contact with patients, particularly nursing students [27]. Nursing students—as future health care providers - will play a key role in health promotion and their attitude towards health promotion highly influences their health and performance, health status of the general population as well as the hospitalized patients [27] [15] [16]. To achieve their role effectively, nursing students should be equipped with knowledge and skills about health-promoting practices during their studying years [27] [15].

Several studies investigated health-promoting behaviours among nursing and other health sciences university students. In Thailand, studies showed that nursing students and physical therapy students demonstrated moderate level of health-promoting behaviours [15] [17] [18]. Similar findings were reported in studies conducted in Turkey on dental students [19] and nursing students [20]. On the other side, a study conducted in Iran reported that nursing and other health science students had poor level of health-promoting behaviours [16]. When comparing nursing and non-nursing students, a study conducted in Turkey found that a sample of 847 nursing students have significantly higher life styles behaviours scores than a matching sample of 769 students from the schools of social sciences [21]. In the same line, a survey in Greece that included 300 university students demonstrated that fewer medical students reported drinking alcohol and smoking than other students [11]. To understand the health promotion life style of students across cultures, a Jordanian study compared health-promoting practices of Canadian and Jordanian nursing students. The study showed significant differences between the two groups of students regarding health responsibility, physical activity, and interpersonal relations [22].

Nursing curriculum covers the concepts of health promotion in many courses. Despite that, nursing students may not get benefits from them in their own life [23]. Studies confirmed that nursing students engaged in unhealthy life style practices like smoking, physical inactivity, and unhealthy food [20] [24]. On the other side, enhancing curriculum that focus on health promotion concept will improve students' awareness of practicing healthy lifestyle. This may ultimately lead to better health outcomes of the students as well as their clients [25].

In agreement to that, study conducted in Turkey reported a positive effect of coursework about an early diagnosis in cancer on health-promoting behaviours of students who study health management [26]. Similar study conducted in our country to evaluate the effect of educational programme on healthy lifestyle behaviours of university students indicated a slight positive impact of the programme on nutritional habits of the students [12]. Other study in Taiwan reported positive impact of health-promotion education on healthy lifestyle behaviours of nursing students and emphasized that health-promotion programms were simple educational strategies for nursing students to adopt [28].

Studies also investigated health-promoting behaviours in relation to socio-demographic factors. When considering gender, female students engaged more in health responsibility behaviours and nutrition than male students who showed higher levels on physical activity than females [11] [19]. While, a study including 307 Mexican university students found that male students displayed overall healthier profile, and better on stress management and exercise than female students [29].

Some studies found that students with high economic status had better health-promoting behaviour scores than those with low economic status [13] [21] [30] [31]. Other studies reported significant differences in healthpromoting behaviours of nursing and physical therapy students according to their study level [5] [15] [18] [21]. The interpersonal relations and health responsibility score averages of nursing students increased as the students' grade level increased [21]. Opposite to that, a study conducted in Japan showed that students in the first year had 
better health-promoting lifestyles than those in other years [14]. Age has been also found to influence healthpromoting behaviours of the university students [13] [21] [24]. For instance, older students indicated better health responsibility but poorer stress management than younger students [21].

It seems that the health-promoting behaviours of nursing and health sciences university students are receiving an increased attention worldwide. However, this area is still under search in our country; therefore, this study aimed to: a) assess university nursing students' current health-promoting behaviours; b) find out if there is a difference in nursing students' health-promoting behaviours according to age, gender, study level, and family's monthly income.

\section{Methods}

A cross-sectional descriptive design was used in this study. The target population was university nursing students with the following eligibility criteria: students who enrolled in nursing undergraduate program and agreed to participate in the study. Yet, students who had medical diagnosis were excluded from the study because this may affect their participation in health-promoting behaviours. Convenience sample of 167 students from two public universities and one private university in Jordan participated in the study.

Prior to data collection, ethical approval was obtained from the Research Committee at the Faculty of Nursing and the Research Ethical Committee at the Deanship of Academic Research at the University where the authors work. The informed consent of the students was obtained prior to data collection. Students were approached during lecture time and invited to participate in the study. They were advised of the purpose of the study and were told that participation is voluntary. They had the right to withdraw at any time without adverse impact on their study, and information was confidential and anonymous.

Data were collected using self-administered questionnaire by trained research assistants at the beginning of the class. After the completion, the students returned the questionnaire in a sealed envelope. Data were collected between September 2013 and January 2014. Data collectors avoided the periods of midterm and final exams that imposed the students to stresses that may affect the efficiency of data collection process.

The questionnaire of the study has two sections. The first section contained questions on demographic characteristics of the study participants (gender, age, place of residence, family's monthly income, marital status, and family medical history) that developed by the authors of this study.

Health-promoting behaviours of nursing students were assessed in the second section of the questionnaire by Health Promoting Lifestyle Profile II (HPLP II). This self-administered questionnaire was developed by Walker, Sechrist, and Pender [32]. It consists of 52 items divided into six subscales including health responsibility (9 items), physical activity (8 items), nutrition (9 items), spiritual growth (9 items), interpersonal relations (9 items), and stress management ( 8 items). The scale measures health-promoting behaviours on a four point Likert scale range from never to routinely. A score for overall health-promoting behaviours is obtained by calculating the mean of the individual's responses to all fifty-two items. The six subscales scores are obtained similarly by calculating a mean of the responses to subscales items.

The questionnaire was administered to students in Arabic language although they study in English, since English is not their native language. The reliability and validity of the Arabic version was established by a previous study conducted in Jordan [22]. In the current study, the Cronbach's alpha coefficient was 0.92 for the total scale and ranged from 0.65 to 0.83 for the subscales.

Data were analyzed by using the Statistical Package for Social Science (SPSS) version 17. A composite score for HPLP II was obtained as well as individual subscales scores. Descriptive statistics (percentage, mean, standard deviation, minimum, and maximum) were used to describe socio-demographics characteristics and HPLP II. The correlation between the HPLP II and socio-demographic variables was tested by the Pearson's product moment correlation. Independent sample t-test was used to determine associations and differences in the HPLP II according to demographic characteristics. Moreover, analysis of variance (ANOVA) was used to test significant differences in the HPLP II mean scores of students according to study level. Findings were considered statistically significant if the $P$ value was $\leq 0.05$.

\section{Results}

This study included 167 nursing students and most of them were fourth year nursing students $(37.7 \%, n=63)$. Descriptive characteristics of the study participants (Table 1$)(\mathrm{N}=167)$ showed that female students compro- 
mised $76 \%(n=127)$, while male students compromised $24 \%(n=40)$ of the study sample. Also, this study revealed that the mean score of monthly family’s income was $662.90 \pm 647.129$ (100 - 5000) Jordan Dinar (JD).

The study aimed to identify the students' health-promoting behaviours, therefore, results showed the mean of total HPLP II was $127.24 \pm 21.03$ (range: 53 - 189). The highest mean in the subscales was $(25.04 \pm 4.70)$ for spiritual growth but the lowest was $(16.27 \pm 5.21)$ for physical activity. The mean item score for each subscale is presented in Table 2.

To find out if there is a difference in nursing students' health-promoting behaviours according to sociodemographic characteristics, results in Table 3 showed no statistically significant difference was found between gender and total score average of HPLP II. Yet, score average of male students was higher than that of female students in health responsibility and stress management subscales and this difference was statistically significant. In the same stream, Pearson's correlation results showed a statistically significant negative correlation between students' age and interpersonal subscale only. On the other side, no statistical significant difference was found between HPLP II total score and the subscales mean scores and students' study level and family's monthly income.

\begin{tabular}{lcc}
$\begin{array}{l}\text { Table 1. Frequency distribution of students' socio-demographic characteristics } \\
(\mathrm{N}=167) .\end{array}$ & Students $(\mathrm{N})$ & \\
\hline Characteristic & & 24 \\
\hline Gender & 40 & 76 \\
Male & 127 & \\
Female & & 19.2 \\
Grade & 32 & 19.8 \\
$1^{\text {st }}$ year & 33 & 23.4 \\
$2^{\text {nd }}$ year & 39 & 37.7 \\
$3^{\text {rd }}$ year & 63 & \\
$4^{\text {th }}$ year & 148 & 88.6 \\
Marital status & 17 & 10.2 \\
Single & 2 & 1.2 \\
Married & & \\
Divorced & & \\
\hline
\end{tabular}

$\%$, Percentage.

Table 2. Nursing students HPLP II total and subscales’ mean scores $(\mathrm{N}=167)$.

\begin{tabular}{|c|c|c|c|c|c|c|}
\hline Rank Order & HPLP and subscales & $(\chi)$ & (SD) & (Min) & (Max) & $\begin{array}{l}\text { Highest and lowest } \\
\text { obtainable score }\end{array}$ \\
\hline & Total HPLP score (52 items) & 127.24 & 21.03 & 53 & 189 & $52-208$ \\
\hline 1 & Spiritual growth (9 items) & 25.04 & 4.70 & 9 & 36 & $9-36$ \\
\hline 3 & Health responsibility (9 items) & 22.07 & 4.80 & 9 & 33 & $9-36$ \\
\hline 6 & Physical activity (8 items) & 16.27 & 5.21 & 8 & 31 & $8-32$ \\
\hline 4 & Nutrition (9 items) & 20.96 & 4.26 & 9 & 32 & $9-36$ \\
\hline 2 & Interpersonal relations (9 items) & 24.18 & 4.22 & 9 & 35 & $9-36$ \\
\hline 5 & Stress management (8 items) & 18.66 & 3.75 & 8 & 30 & $8-32$ \\
\hline
\end{tabular}

HPLP, Health promotion life-style Profile; $\chi$, Mean; SD, standard deviation; min, minimum; max, maximum. 
Table 3. Associations and differences of HPLP II total score and subscales' mean scores with demographic variables $(\mathrm{N}=$ 167).

\begin{tabular}{cccccccc}
\hline $\begin{array}{c}\text { Descriptive } \\
\text { feature }\end{array}$ & Spiritual growth & $\begin{array}{c}\text { Health } \\
\text { responsibility }\end{array}$ & $\begin{array}{c}\text { Physical } \\
\text { activity }\end{array}$ & Nutrition & $\begin{array}{c}\text { Interpersonal } \\
\text { relations }\end{array}$ & $\begin{array}{c}\text { Stress } \\
\text { management }\end{array}$ & HPLP total \\
\hline Age & & & & & & & \\
r & -0.147 & 0.012 & -0.092 & -0.006 & $-0.175^{*}$ & -0.132 & -0.113 \\
P & 0.058 & 0.887 & 0.239 & 0.932 & 0.024 & 0.089 & 0.146 \\
Gender & & & & & & & \\
Male & $26.15 \pm 4.46$ & $23.60 \pm 4.11$ & $17.27 \pm 4.88$ & $21.02 \pm 3.64$ & $24.75 \pm 4.86$ & $19.77 \pm 3.87$ & $132.57 \pm 20.04$ \\
Female & $24.69 \pm 4.74$ & $21.59 \pm 4.92$ & $15.96 \pm 5.29$ & $20.95 \pm 4.45$ & $24.00 \pm 4.00$ & $18.31 \pm 3.66$ & $125.55 \pm 21.14$ \\
t & 1.717 & 2.327 & 1.394 & 0.094 & 0.969 & 2.167 & 1.852 \\
P & 0.088 & $0.021^{*}$ & 0.165 & 0.926 & 0.334 & $0.032 *$ & 0.066 \\
\hline
\end{tabular}

HPLP, Health promotion life-style Profile; ${ }^{*}$ Correlation is significant at the 0.05 level (2-tailed).

\section{Discussion}

This study intended to identify nursing students' health-promoting behaviours. Most of the study sample was females. This indicates that higher percentage of females is studying nursing in Jordan, which reflects the Ministry of Higher Education policy regarding the acceptance of nursing students at universities, where females' proportion is not less than 70\% [33]. The mean score for the HPLP II showed that students practiced healthpromoting behaviours at a moderate level. Congruent results were reported in previous studies [15] [17] [19] [20]. Nevertheless, nursing students have significantly higher life style behaviours scores than non-nursing university students [21]. On the other side, nursing students reported low level of health-promoting life style total score [16] [24].

Regarding the subscales of HPLP II, the students had the highest scores on spiritual growth, which was consistent with previous studies conducted in Jordan [22] [34]. Islam is the primary religion in Jordan and has a direct implication on values, beliefs, daily practices and health-promoting behviours of the people. For example, Islam prohibits alcohol. This finding is supported with other studies around the world [14] [16] [21]. Some studies reported that nursing students scored higher on other subscales of HPLP II such as health responsibility, nutrition, stress management and self-actualization [8] [16] [20] [21]

The students of current study reported the lowest scores on the physical activity subscale. Similar findings were reported from previous Jordanian studies [9] [22] [34]. For example, Jordanian adults reported less participation in physical activity [32]. At school level, a study assessed physical activity of adolescents in schools in Jordan showed that the majority of students were not engaged in physical activities either in or outside schools [9]. This result can be explained from the cultural and social context as regular exercise habits are not integrated in the daily life of Jordanian people and sport to some extent still as leisure activity. Besides that, it is not easy to access to community sport centers that need fees for practicing sporting activities. Other explanation could be that our nursing students have extensive theoretical and clinical schedule, so they may feel exhausted to practice activity exercises. Congruent findings were obtained with a group of nursing and midwifery students in Turkey [20]. Similar finding was also confirmed by studies conducted in different countries [15] [19] [26].

Age was not found to have statistically significant relationship with total score of HPLP II. However, there was a statistically significant negative correlation between students' age and interpersonal relations subscale only. Similarly, younger nursing students reported significant differences on stress management, physical activity and health responsibility behaviours [21]. On the other hand, older students reported higher level of overall health-promoting lifestyles than younger students by other studies [13] [17]. However, no correlation was found between the age of the university students and total score of HPLP II [14]. These contradicting results from studies may mandate the need for more researches in this area.

There was no statistically significant difference between male and female students on the total score of HPLP II. However, health responsibility and stress management score averages of male students were higher than that of female students and this difference was statistically significant. It can be explained that female students are 
overloaded by studying and other responsibilities towered their families; female is expected to assist in house duties and taking care of siblings for the purpose of preparing her to fit her future role as she becomes a wife and a mother. This, in turn, may make female student tired and stressed and even does not have time and energy to take care of her health and psychological well-being. Similarly, studies in Turkey and Japan [13] [14] showed that physical activity score average was higher in male students compared to female students in both studies and this difference was statistically significant. Whereas, other study showed no significant differences in physical activities and nutritional habits and gender among university students [12]. Inversely, the score average of female students was higher than that of male students in the subscales of nutrition, self-actualization, health responsibility, interpersonal relations, and stress management in other studies [11] [13] [18] [19] [21].

This study includes the following limitations. First, the sample selected from three universities, however, probability sample with larger sample size might provide better understanding and information. Second, the cross-sectional design may compromise the ability to generalize the study findings. Finally, most of the study sample was females, which may bias results since gender related differences were found in health responsibility and stress management subscales.

\section{Conclusion}

This study may reflect accumulative effect of many variables that contribute to the health-promoting behaviours of nursing students. The study may provide a guideline to staff and administrators in the universities to set up more effective strategies for the sake of improving health-promotion behaviours of the nursing students. Quantitative and qualitative studies are needed to shape a holistic picture on the health life style of the students. Furthermore, longitudinal studies are recommended to gain an insight on changes of health-promoting behaviours of nursing students over time. Additional studies also suggested determining whether differences in healthpromoting behaviours between nursing and non-nursing students existed or not. The study also recommended the establishment of physical facilities in universities' campuses to encourage students to improve their physical activities.

\section{Acknowledgements}

The authors would like to acknowledge the students who participated in this study. Our grateful thanks are extended the Deanship for Scientific Research-University of Jordan for funding this study.

\section{References}

[1] Asgari, F., Aghajani, H., Haghazali, M. and Heidarian, H. (2009) Non-Communicable Diseases Risk Factors Surveillance in Iran. Iranian Journal of Public Health, 38, 119-122.

[2] World Health Organization (2013) Noncommunicable Diseases. http://www.who.int/mediacentre/factsheets/fs355/en/

[3] Department of Statistics (2014) Latest News and Indicators. http://www.dos.gov.jo/dos home e/main/

[4] Eastern Mediterranean Public Health Network \& Higher Population Council (2013) Projecting the Prevalence of Major Non-Communicable Diseases/Risk Factors for the Jordanian Youth Population for the Years 2007-2050. Eastern Mediterranean Public Health Network a Seventh Global Scientific Conference, 2012, Jordan, 1-28.

[5] Alpar, Ş.E., Şenturan, L., Karabacak, Ü. and Sabuncu, N. (2008) Change in the Health Promoting Lifestyle Behaviour of Turkish University Nursing Students from Beginning to End of Nurse Training. Nurse Education in Practice, 8, 382-388. http://dx.doi.org/10.1016/j.nepr.2008.03.010

[6] Pender, N.J., Murdaugh, C.L. and Parsons, M.A. (2011) Health Promotion in Nursing Practice. 6th Edition, Pearson, Boston.

[7] Pender, N. (1996) Health Promotion in Nursing Practice. 3rd Edition, Appleton \& Lange, Stamford.

[8] Wang, D., Xing, X. and Wu, X. (2013) Healthy Lifestyles of University Students in China and Influential Factors. The Scientific World Journal, 2013, 10 p. http://dx.doi.org/10.1155/2013/412950

[9] Haddad, L., Owies, A. and Mansour, A. (2009) Wellness Appraisal among Adolescents in Jordan: A Model from Developing Country: A Cross-Sectional Questionnaire. Health Promotion International, 24, 130-139 http://dx.doi.org/10.1093/heapro/dap013

[10] Lynn, R. and Sharon, D. (2003) Youth Resilience Framework for Reducing Health-Risk Behaviors in Adolescents. 
Journal of Pediatric Nursing, 18, 379-387. http://dx.doi.org/10.1016/S0882-5963(03)00162-3

[11] Tirodimos, I., Georgouvia, I., Savvala, T.-N., Karanika, E. and Noukari, D. (2009) Healthy Lifestyle Habits among Greek University Students: Differences by Sex and Faculty of Study. Eastern Mediterranean Health Journal, 15, 722728.

[12] Abu-Moghli, F.A., Khalaf, I.A. and Barghoti, F.F. (2010) The Influence of a Health Education Programme on Healthy Lifestyles and Practices among University Students. International Journal of Nursing Practice, 16, 35-42. http://dx.doi.org/10.1111/j.1440-172X.2009.01801.x

[13] Hacıhasanoğlu, R., Yıldırım, A., Karakurt, P. and Sağlam, R. (2011) Healthy Lifestyle Behavior in University Students and Influential Factors in Eastern Turkey. International Journal of Nursing Practice, 17, 43-51. http://dx.doi.org/10.1111/j.1440-172X.2010.01905.x

[14] Wei, C.-N., Harada, K., Ueda, K., Fukumoto, K., Minamoto, K. and Ueda, A. (2012) Assessment of Health-Promoting Lifestyle Profile in Japanese University Students. Environmental Health and Preventive Medicine, 17, 222-227. http://dx.doi.org/10.1007/s12199-011-0244-8

[15] Wittayapun, Y., Tanasirirug, V., Butsripoom, B. and Ekpanyaskul, C. (2013) Factors Affecting Health-Promoting Behaviors in Nursing Students of the Faculty of Nursing, Srinakharinwirot University, Thailand. Journal of Public Health, 40, 215-225.

[16] Rezaei-Adaryani, M. and Rezaei-Adaryani, M. (2012) Health-Promoting Lifestyle of a Group of Iranian Medical, Nursing and Allied Health Students. Journal of Clinical Nursing, 21, 3587-3589. http://dx.doi.org/10.1111/j.1365-2702.2012.04176.x

[17] Hong, J., Sermsri, S. and Keiwkarnka, B. (2007) Health-Promoting Lifestyles of Nursing Students in Mahidol University. Journal of Public Health and Development, 5, 27-40.

[18] Thanawat, T., Nualnetr, N. and Eungpinichpong, W. (2009) Health-Promoting Behaviors of Physical Therapy Students in Khon Kaen University. Journal of Medical Technology and Physical Therapy, 21, 268-276.

[19] Peker, K. and Bermek, G. (2011) Predictors of Health-Promoting Behaviors among Freshman Dental Students at Istanbul University. Journal of Dental Education, 75, 413-420.

[20] Karadăg, M. and Yildirim, N. (2010) Health Behaviors in Health Sciences University Students in Turkey. Social Behavior \& Personality: An International Journal, 38, 43-51.

[21] Can, G., Ozdilli, K., Erol, O., Unsar, S., Tulek, Z., Savaser, S. and Durna, Z. (2008) Comparison of the Health-Promoting Lifestyles of Nursing and Non-Nursing Students in Istanbul, Turkey. Nursing \& Health Sciences, 10, 273-280. http://dx.doi.org/10.1111/j.1442-2018.2008.00405.x

[22] Haddad, L., Kane, D., Rajacich, D., Cameron, S. and Al-Ma’aitah, R. (2004) A Comparison of Health Practices of Canadian and Jordanian Nursing Students. Public Health Nursing, 21, 85-90. http://dx.doi.org/10.1111/j.1525-1446.2004.21112.x

[23] Bryer, J., Cherkis, F. and Raman, J. (2013) Health-Promotion Behaviors of Undergraduate Nursing Students: A Survey Analysis. Nursing Education Perspectives, 34, 410-415. http://dx.doi.org/10.5480/11-614

[24] Al-Kandari, F., Vidal, V.L. and Thomas, D. (2008) Health-Promoting Lifestyle and Body Mass Index among College of Nursing Students in Kuwait: A Correlational Study. Nursing \& Health Sciences, 10, 43-50. http://dx.doi.org/10.1111/j.1442-2018.2007.00370.x

[25] Robiner, W., Lazear, S. and Duffy, B. (2013) Promoting Health Behaviors in Medical Education. Clinical Teaching, 10, 160-164. http://dx.doi.org/10.1111/j.1743-498X.2012.00637.x

[26] Ozveren, H., Cerit, B. and Ertop, N.G. (2013) Differences in Health Promoting Lifestyle Behavior of Health Management Students Based upon Early Diagnosis Coverage in a Cancer Course. Asian Pacific Journal of Cancer Prevention, 14, 5769-5773. http://dx.doi.org/10.7314/APJCP.2013.14.10.5769

[27] Hosseini, M., Torab, T.A., Taghdisi, M.H. and Vardanjani, S.A.E. (2013) Study on Situational Influences Perceived in Nursing Discipline on Health Promotion: A Qualitative Study. International Scholarly Research Notices Nursing, 2013, Article ID: 218034. http://dx.doi.org/10.1155/2013/218034

[28] Yeh, L., et al. (2005) A Preliminary Study of a Healthy-Lifestyle-Promoting Program for Nursing Students in Taiwan. Journal of Nursing Education, 44, 563-565.

[29] Ulladi'ez, S. and Pe'rez-fortis, A. (2009) Socio-Demographic Predictors of Health Behavior in Mexican College Students. Health Promotion International, 25, 85-93. http://dx.doi.org/10.1093/heapro/dap047

[30] Ayaz, S., Tezcan, S. and Akınc, F. (2005) Health Promotion Behavior of Students at the Nursing College, Cumhuriyet University. Journal of Nursing School, 9, 26-34.

[31] Johnson, R. (2005) Gender Differences in Health-Promoting Lifestyles of African Americans. Public Health Nursing, 22, 130-137. http://dx.doi.org/10.1111/j.0737-1209.2005.220206.x 
[32] Walker, S.N., Sechrist, K.R. and Pender, N.J. (1987) The Health-Promoting Lifestyle Profile: Development and Psychometric Characteristics. Nursing Research, 36, 76-81. http://dx.doi.org/10.1097/00006199-198703000-00002

[33] Ministry of Higher Education and Scientific Research (2014) http://www.mohe.gov.jo/HomePage/tabid/36/language/en-US/Default.aspx

[34] Ammouri, A. (2008) Demographic Differences in Health Promoting Lifestyle of Adult Jordanians. Jordanian Medical Journal, 42, 1-9. 
Scientific Research Publishing (SCIRP) is one of the largest Open Access journal publishers. It is currently publishing more than 200 open access, online, peer-reviewed journals covering a wide range of academic disciplines. SCIRP serves the worldwide academic communities and contributes to the progress and application of science with its publication.

Other selected journals from SCIRP are listed as below. Submit your manuscript to us via either submit@scirp.org or Online Submission Portal.
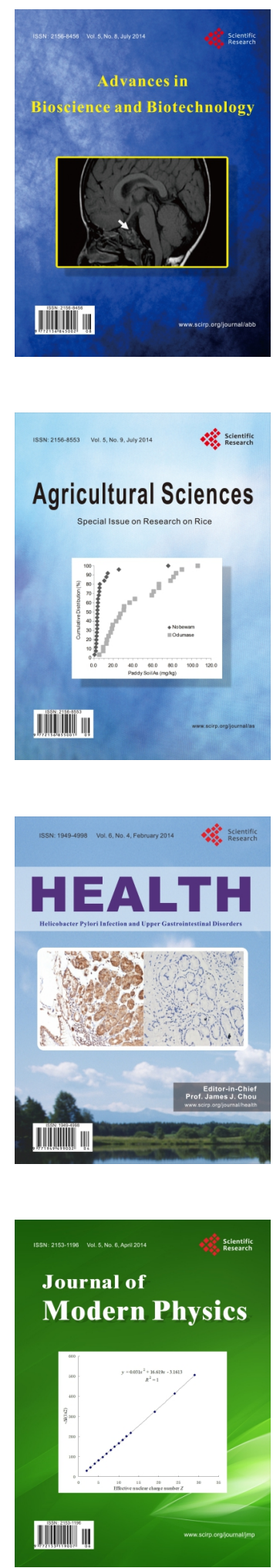
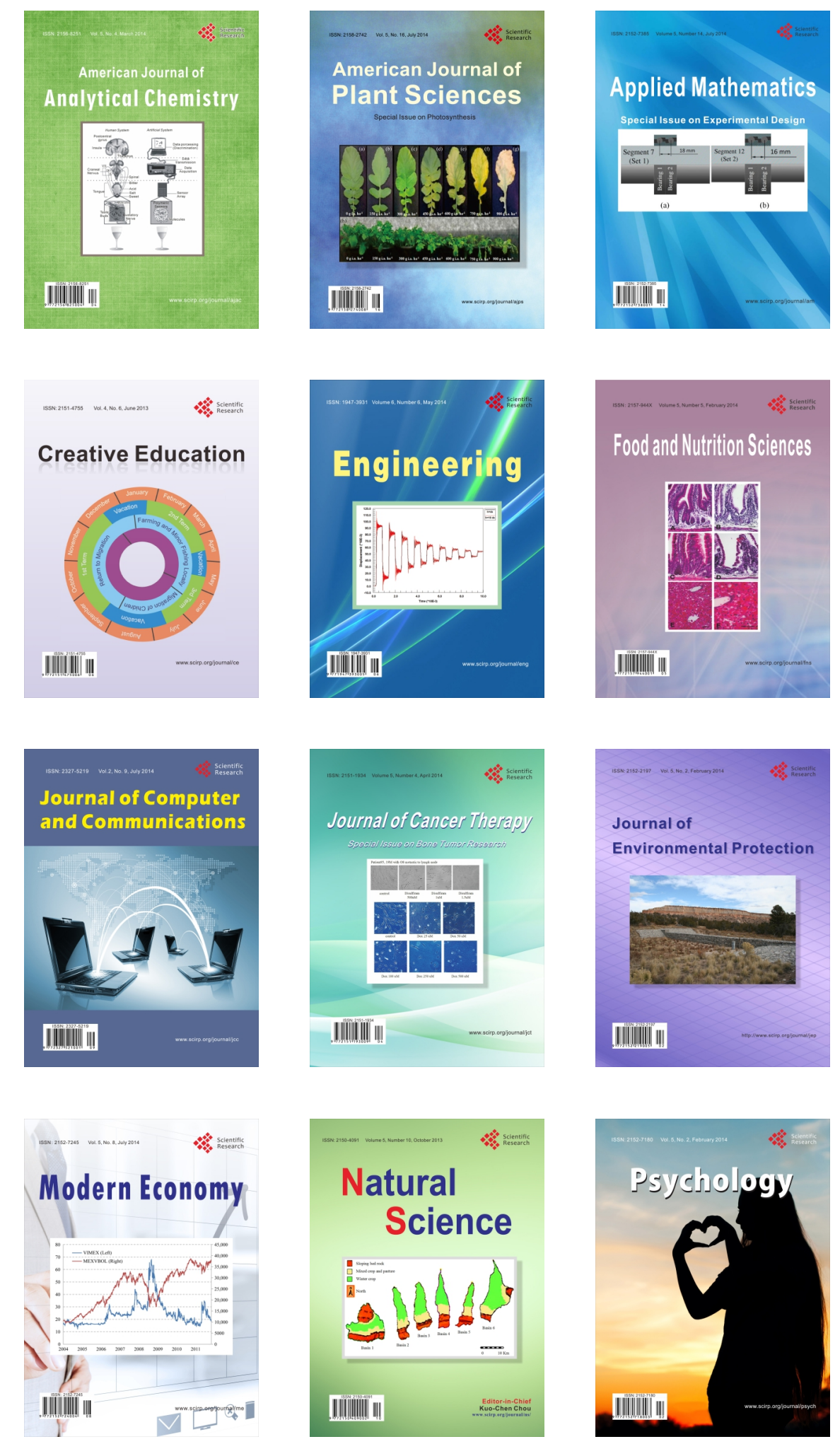